\title{
Estimativa de anisotropia local através de dados de ondas qP medidos em experi- mentos de VSP multiazimutal
}

Adriano C. R. Barreto ${ }^{1}$, Raíza de N. A. Macambira ${ }^{1}$, Ellen N. S. Gomes ${ }^{1}$ e Ivan Pšenčík ${ }^{2}$.

(1) Universidade Federal do Pará (UFPA), (2) Geophysical Institute, Acad. Sci. of Czech Republic.

\section{FUNDAMENTOS TEÓRICOS}

Copyright 2010, SBGf - Sociedade Brasileira de Geofísica.

Este texto foi preparado para a apresentação no IV Simpósio Brasileiro de Geofísica, Brasília, 14 a 17 de novembro de 2010. Seu conteúdo foi revisado pelo Comitê Técnico do IV SimBGt, mas não necessariamente representa a opinião da SBGf ou de seus associados. É proibida a reprodução total ou parcial deste material para propósitos comerciais sem prévia autorização da SBGf.

\section{ABSTRACT}

Inversion scheme for the determination of anisotropy in a vicinity of a receiver situated in a borehole from the data obtained during a multiazimuth multiple-source offset VSP experiment is studied. The data consist of vertical components of slowness vectors of direct and reflected $\mathrm{qP}$ waves. We analyze the effects of choice of a reference medium and of the wave normal on the results of inversion. We also study sensitivity of the inversion scheme to the number and orientation of profiles, to the number of sources along the profiles and to the number and type of waves considered. Study of the stability of the inversion scheme indicates which parameters of the medium can be recovered reliably and which cannot.

\section{INTRODUÇÃO}

Neste trabalho é feita a estimativa de anisotropia local para meios anisotrópicos arbitrários em experimentos de VSP com múltiplas fontes a partir da relação linear entre os parâmetros elásticos do meio, a componente vertical do vetor vagarosidade e o vetor de polarização de ondas do tipo qP. Os dados observados foram gerados sinteticamente e obtidos de fontes distribuídas na superfície em perfis com diferentes azimutes. Este esquema não depende da estrutura do meio acima do geofone, como também não depende da forma do poço. Uma análise de sensibilidade desta formulação é realizada. Por fim, são apresentadas as estimativas e os resultados dos vários testes em que o parâmetros WA foram estimados para um modelo sintético. Para tal considerou-se vários fatores: tipo de onda, grau de anisotropia, nível de ruído nos dados de vagarosidade e polarização. Em todo trabalho, o sistema de coordenadas adotado foi o Cartesiano $\left(x_{1}, x_{2}, x_{3}\right)$ com eixo positivo na direção que aponta de cima para baixo e as matrizes são representadas por letras maiúsculas e os vetores são representados por letras minúsculas ambos em negrito. Utilizase a notação indicial e a convecção da soma (Aki and Richards, 1980) em todo o texto. As exceções a estas regras serão indicadas explicitamente.
Considerando três vetores unitários perpendiculares entre si: $\mathbf{e}^{(1)}, \mathbf{e}^{(2)}$ e $\mathbf{e}^{(3)}$, tal que este último é paralelo ao vetor $n_{k},(k=1,2,3)$ normal à frente da onda $\mathrm{P}$ no meio isotrópico de referência. Uma forma de representar estes vetores é apresentada por (Pšenčík and Gajewski, 1998):

$$
\begin{aligned}
\mathbf{e}^{(1)} & =D^{-1}\left(n_{1} n_{3}, n_{2} n_{3}, n_{3}^{2}-1\right) \\
\mathbf{e}^{(2)} & =D^{-1}\left(-n_{2}, n_{1}, 0\right) \\
\mathbf{e}^{(3)} & =\left(n_{1}, n_{2}, n_{3}\right) .
\end{aligned}
$$

Com: $D=\sqrt{n_{1}^{2}+n_{2}^{2}}$ em que $n_{1}$ e $n_{2}$ são as componentes horizontais do vetor frente $\left(n_{k}\right)$ de onda $\mathrm{P}$ no meio isotrópico de referência. Os vetores de vagarosidade e polarização de uma onda qP que se propaga em um meio anisotrópico qualquer, estão relacionados linearmente com os parâmetros WA (parâmetros de fraca anisotropia) do meio através da equação (Gomes et al., 2004):

$D\left(\alpha^{2}-\beta^{2}\right)^{-1} B_{13}-\frac{1}{2} \alpha^{-1} \eta B_{33}=D g_{i} e_{i}^{(1)}+\alpha \Delta \eta$.

Em que: $\alpha$ e $\beta$ são as velocidades das ondas $\mathrm{P}$ e $\mathrm{S}$, respectivamente, no meio de referência, $\eta$ é o comprimento da projeção do vetor de vagarosidade $\left(s_{i}^{0}\right)$ no meio de referência na direção do eixo $x_{3}, \Delta \eta$ é a perturbação de primeira ordem de $\eta, g_{i}$ é a i-ésima componente do vetor de polarização e $B_{13}$ e $B_{33}$ são os elementos da matriz de fraca anisotropia.

\section{Modelo Direto}

A equação (2) pode ser escrita na forma matricial:

$$
M_{i j} p_{j}=y_{i} \text {. }
$$

Em que, $y_{i}$ é a i-ésima componente do vetor das observações formado pelo lado direito de (3), $p_{j}$ é a j-ésima componente do vetor dos 15 parâmetros WA da onda qP, que estão disposto na forma (Pšenčík and Gajewski, 1998):

$$
\begin{array}{ccc}
p_{1}=\epsilon_{x} & p_{2}=\epsilon_{y} & p_{3}=\epsilon_{z} \\
p_{4}=\delta_{x} & p_{5}=\delta_{y} & p_{6}=\delta_{z} \\
p_{7}=\chi_{x} & p_{8}=\chi_{y} & p_{9}=\chi_{z} \\
p_{10}=\epsilon_{15} & p_{11}=\epsilon_{16} & p_{12}=\epsilon_{24} \\
p_{13}=\epsilon_{26} & p_{14}=\epsilon_{34} & p_{15}=\epsilon_{35}
\end{array}
$$


A matriz $M_{i j}\left(\alpha, \beta, n_{k}\right)$, formada pelo lado esquerdo de (3) é a matriz de sensibilidade. Ela dependente dos parâmetros do meio de referência e da geometria de levantamento. O objetivo deste trabalho é estimar os parâmetros WA a partir de dados de VSP Walkaway, através da inversão da equação (3).

\section{Modelo Inverso}

Os parâmetros WA podem ser estimados a partir de (3), determinando-se que valores do vetor $p_{j}$ que minimizam a função:

$$
\Phi=\left\|\sum_{i=1}^{N}\left(y_{i}-M_{i j} \tilde{p_{j}}\right)\right\|_{2}
$$

em que o subscrito 2 refere-se a norma euclidiana, $\mathrm{N}$ é o número de observações e $\tilde{p}_{j}$ são as estimativas dos parâmetros WA. Para se estimar o vetor $p_{j}$ é necessário que toda a matriz $M_{i j}\left(\alpha, \beta, n_{k}\right)$ seja conhecida e, portanto, os parâmetros do meio de referência (velocidades das ondas $\mathrm{P}$ e $\mathrm{S}$ e $n_{k}$, vetor normal à frente de onda $\mathrm{P}$ ) sejam conhecidos. Existem várias maneiras de se determinar esses parâmetros.

\section{Escolha do vetor $\left(n_{k}\right)$ no meio de referência}

$O$ vetor normal à frente de onda $\mathrm{P}$ no meio de referência, $n_{k}$, pode ser escolhido de três formas diferentes:

- Calculado geometricamente. Para esta representação do vetor $n_{k}$, pressupõe-se que o meio é homogêneo. Para meios heterogêneos é feita uma aproximação por raio reto e, quanto maior for o grau de heterogeneidade, menos exata será esta aproximação.

- Supondo conhecido o meio de referência, o vetor $n_{k}$, pode ser calculado através do traçamento de raio no meio de referência. Essa escolha traz custos computacionais, além disso, em casos reais não se tem conhecimento do meio de referência.

- Calculado paralelo ao vetor de polarização observado $\left(n_{k} / / g_{k}\right)$. Em meios isotrópicos tem-se que o vetor normal à frente de onda $\mathrm{P}$ é paralelo a sua direção de polarização, desta forma, essa escolha será tanto melhor quanto mais fraca for a anisotropia.

\section{Escolha da velocidade da onda $\mathbf{P}$ no meio de refer- ência}

Para meios fracamente anisotrópicos, uma boa aproximação da velocidade da onda $P$ no meio de referência é dada pela relação:

$$
s_{z}^{i}=g_{z}^{i} \alpha^{-1}
$$

Em que $s_{i}^{z}$ e $g_{i}^{z}$ são as componentes verticais da i-ésima observação dos vetores de vagarosidade e polarização, respectivamente. A velocidade $\alpha$ no meio de referência pode então ser estimada a partir da equação (6) por mínimos quadrados para $\mathrm{N}$ observações.

Uma outra forma de se estimar $\alpha$ é apresentada em (Zheng \& Pšenčík, 2002) dada por:

$$
\alpha=\frac{1}{N} \sum_{i=1}^{N} \frac{g_{z}^{i}}{s_{z}^{i}}
$$

Verifica-se no entanto, que a estimativa de $\alpha$ feita através de (6) é menos sensível à presença de ruído nos dados de polarização e vagarosidade que a estimativa a partir de (7). O grau de sensibilidade ao ruído das duas equações acima é mostrado numericamente na próxima seção. Quanto a velocidade da onda S, esta foi calculada através da razão de Poisson, $\beta=\alpha / \sqrt{3}$.

Assim, as escolhas feitas para os valores do meio de referência neste trabalho são baseados apenas nos dados observados sem fazer qualquer pressuposto sobre o meio a ser estimado.

\section{TESTES NUMÉRICOS}

O modelo geológico utilizado é formado por duas camadas separadas por uma interface situada a $5 \mathrm{~km}$ de profundidade. O meio acima da interface é anisotrópico e o meio subjacente é um isotrópico que apresenta velocidade de onda $\mathrm{P} \alpha$ igual a $4,0 \mathrm{~km} / \mathrm{s}$ e velocidade de onda $\mathrm{S} \beta$ igual a $2,35 \mathrm{~km} / \mathrm{s}$. O topo e a base da camada acima da interface são compostas por um meio TIV, com anisotropia em torno de $8 \%$.

A configuração utilizada na aquisição é similar a usada em Zheng \& Pšenčík (2002). Consideramos 5 perfis situados na superfície com seus centros na boca do poço e distribuídos ao longo da superfície com ângulos de $0^{\circ}$, $30^{\circ}, 60^{\circ}, 120^{\circ}$ e $150^{\circ}$. Cada perfil contém 9 fontes posicionadas em ambos os lados do poço, separadas de 0,1 $\mathrm{km}$ e iniciando em $0,1 \mathrm{~km}$. No poço existem 13 receptores de três componentes separados de $0,05 \mathrm{~km}$, sendo o primeiro começando na profundidade de $0,1 \mathrm{~km}$.

Nas inversões foram utilizados dados de polarização e vagarosidade de ondas $\mathrm{qP}$ diretas e refletidas em experimentos de VSP Walkaway multiazimutal. Esses dados foram gerados com o uso do pacote ANRAY modificado (Gajewski e Pšenčík, 1990).

O ruído foi aplicado diretamente aos dados de vagarosidade e polarização, tanto nas ondas diretas como nas refletidas. A aplicação de ruído na polarização está ligada à mudança de direção do vetor da polarização. Deste modo, foram utilizados 4 diferentes níveis de ruído, sendo o nível de ruído nas ondas refletidas o dobro das ondas diretas, tanto na vagarosidade, como também na polarização. O uso destes níveis de ruído é justificado pelo fato das ondas refletidas apresentarem maior tempo de trânsito e simular o que acontece em geral em dados reais onde ondas refletidas apresentam maior dificuldade em serem medidas. Para evitar uma leitura cansativa de muitas tabelas, apresentamos apenas as tabelas com 
os resultados das inversões para os receptores 1, 7 e 13, para o nível de ruído nas ondas diretas de $5 \%$ na vagarosidade e $1^{\circ}$ na polarização e nas ondas refletidas $10 \%$ na vagarosidade e $2^{\circ}$ na polarização.

\section{OUTROS TESTES}

Para vários perfis, foram feitos vários testes em que os parâmetros WA foram estimados considerando-se os fatores:

- Inversão a partir de dados de onda qP direta e onda qP refletida.

- Diferentes níveis de ruído aplicados tanto a vagarosidade quanto a polarização.

Os resultados obtidos foram:

1. A estimativa dos parâmetros WA usando apenas dados de onda direta perde um pouco em resolução e estabilidade quando comparada com a estimativa da inversão conjunta, feita de dados de onda direta e refletida. Mas é a estimativa feita apenas de dados de onda refletida que é mais pobre quando comparada com a inversão conjunta.

2. Quanto ao nível de ruído nos dados, verifica-se que os parâmetros WA podem ser estimados para níveis de ruído moderado nos dados de vagarosidade e polarização. Isto corresponde a $20 \%$ do desvio padrão dos dados de vagarosidade e de até $4^{0}$ de diferença na direção dos dados de polarização.

Quando o nível de ruído nos dados de vagarosidade é de apenas $10 \%$ do desvio padrão das observações, os parâmetros WA podem ser bem estimados para erro na direção de polarização de até $5^{0}$. Quando o nível de ruído nos dados de polarização altera a direção de $2^{0}$, o erro na vagarosidade pode ser de até $50 \%$ e ainda assim têm-se parâmetros WA bem estimados. Assim, conclui-se que, a inversão e mais sensível a ruído de polarização do que vagarosidade. Acreditase que isto se deva ao fato de estarmos contaminando os dados de polarização e vagarosidade diretamente e assim a matriz $M_{i j}$ é também contaminada.

\section{DISCUSSÕES E CONCLUSÕES}

Após uma análise das tabelas 1, 2 e 3 verificou-se que para os 3 receptores citados anteriormente, o parâmetro melhor estimado foi o $A_{33}$ por apresentar desvio padrão $5 \%$ menor do que seu valor estimado. Os demais parâmetros são instáveis, sendo o $A_{22}$ o que apresenta maior oscilação.

Notou-se também que as estimativas dos parametros são diferentes entre os receptores, pois o receptor 1 estimou bem os parametros $A_{11}, A_{33}, A_{13}+2 A_{55}$ e 0 $A_{12}+2 A_{66}$, já o receptor 7 estimou bem os parametros $A_{11}$ e o $A_{23}+2 A_{44}$, já o receptor 13 estimou bem apenas o parametro $A_{33}$ assim como o receptor 1 , com isso concluimos que o receptor mais proximo da superficie, ou seja, cujo tempo de transito da onda é menor, estimou bem a maioria dos parametros, ja o receptor 13 que precisa de um maior tempo de transito da onda, estimou apenas um parametro, o qual é mais estavel.

\section{AGRADECIMENTOS}

Os autores agradecem ao Conselho Nacional de Desenvolvimento Científico e Tecnológico - CNPq - pelo apoio financeiro e de extrema importância para o desenvolvimento deste projeto.

\section{REFERÊNCIAS}

ZHENG, X. \& PSENCIK, I. 2002.Local determination of weak anisotropy parameters from qP-wave slowness and particle motion measurements. Pure and Applied Geophysics, 159: 1881-1905.

THOMSEN, L. 1986. Weak elastic anisotropy: Geophysics, Soc. of Expl. Geophys., 51: 1954-1966

GOMES, E. N. S. Estimativa de parâmetros elásticos em meios anisotrópicos. Tese de Doutourado. Curso de Pós-Graduação em Geofísica. Universidade Federal do Pará - UFPA, 2003

AKI, K., and RICHARDS, P. G., 1980, Quantitative seismology, theory and methods: Volume 1: W. H. Freeman and Company.

GAJEWSKI, D., and PSENCIK, I., 1990, Vertical seismic profile synthetics by dinamic ray tracing in laterally varying layered anisotropic strutures.: J. Geophys. Res., 67, no. $1,300-306$.

PSENCIK, I., and GAJEWSKI, D., 1998, Polarization, phase velocity and NMO velocity of $\mathrm{qP}$ waves in arbitrary weakly anisotropic media: Geophysics, 63, 1754-1766. 


\begin{tabular}{|c|c|c|c|c|c|c|c|}
\hline WA & EXATO & ESTIM. & D.PADRÃO & PARAM. ELAS. & EXATOS & ESTIM. & D.PADRÃO \\
\hline$\varepsilon_{x}$ & $9,22 \mathrm{E}-002$ & 0,10 & $9,60 \mathrm{E}-002$ & $A_{11}$ & 16,10 & 16,41 & 2,70 \\
\hline$\varepsilon_{y}$ & $9,22 \mathrm{E}-002$ & $4,20 \mathrm{E}-002$ & $3,73 \mathrm{E}-002$ & $A_{22}$ & 16,10 & 14,74 & 1,09 \\
\hline$\varepsilon_{z}$ & $4,71 \mathrm{E}-003$ & $3,52 \mathrm{E}-003$ & $1,18 \mathrm{E}-003$ & $A_{33}$ & 13,72 & 13,68 & 0,19 \\
\hline$\delta_{x}$ & $8,66 \mathrm{E}-002$ & 0,11 & 0,13 & $A_{13}+2 A_{55}$ & 14,77 & 15,10 & 1,87 \\
\hline$\delta_{y}$ & $8,66 \mathrm{E}-002$ & $2,24 \mathrm{E}-002$ & $4,25 \mathrm{E}-002$ & $A_{23}+2 A_{44}$ & 14,77 & 13,90 & 0,65 \\
\hline$\delta_{z}$ & 0,18 & 0,14 & 0,13 & $A_{12}+2 A_{66}$ & 16,09 & 15,51 & 1,98 \\
\hline
\end{tabular}

Tabela 1: Valores exatos e estimados dos parâmetros WA, valores exatos e estimados dos parâmetros elásticos normalizados pela densidade (em $\mathrm{m}^{2} / \mathrm{s}^{2}$ ) e seus respectivos desvios padrões amostral. As velocidades das ondas $\mathrm{P} \mathrm{e}$ S são: $\alpha$ sem ruído $=3,68 \mathrm{~km} / \mathrm{s}$; Velocidade $\alpha$ com ruído $=3,686 \mathrm{~km} / \mathrm{s}$; Velocidade $\beta$ sem ruído $=2,13 \mathrm{~km} / \mathrm{s}$.

\begin{tabular}{|c|c|c|c|c|c|c|c|}
\hline WA & EXATO & ESTIM. & D.PADRÃO & PARAM. ELAS. & EXATOS & ESTIM. & D.PADRÃO \\
\hline$\varepsilon_{x}$ & $9,56 \mathrm{E}-002$ & $6,13 \mathrm{E}-002$ & $8,13 \mathrm{E}-002$ & $A_{11}$ & 17,34 & 16,35 & 2,44 \\
\hline$\varepsilon_{y}$ & $9,56 \mathrm{E}-002$ & $6,53 \mathrm{E}-002$ & 0,10 & $A_{22}$ & 17,34 & 16,46 & 3,04 \\
\hline$\varepsilon_{z}$ & $7,68 \mathrm{E}-003$ & $5,75 \mathrm{E}-003$ & $2,59 \mathrm{E}-003$ & $A_{33}$ & 14,78 & 14,72 & 0,19 \\
\hline$\delta_{x}$ & $9,23 \mathrm{E}-002$ & $5,14 \mathrm{E}-002$ & 0,11 & $A_{13}+2 A_{55}$ & 15,90 & 15,31 & 1,77 \\
\hline$\delta_{y}$ & $9,23 \mathrm{E}-002$ & $5,82 \mathrm{E}-002$ & 0,14 & $A_{23}+2 A_{44}$ & 15,90 & 15,41 & 2,22 \\
\hline$\delta_{z}$ & 0,19 & 0,13 & 0,14 & $A_{12}+2 A_{66}$ & 17,33 & 16,49 & 2,17 \\
\hline
\end{tabular}

Tabela 2: Valores exatos e estimados dos parâmetros WA, valores exatos e estimados dos parâmetros elásticos normalizados pela densidade (em $\mathrm{m}^{2} / \mathrm{s}^{2}$ ) e seus respectivos desvios padrões amostral. As velocidades das ondas $\mathrm{P} \mathrm{e}$ S são: $\alpha$ sem ruído $=3,814 \mathrm{~km} / \mathrm{s}$; Velocidade $\alpha$ com ruído $=3,815 \mathrm{~km} / \mathrm{s}$; Velocidade $\beta$ sem ruído $=2,20 \mathrm{~km} / \mathrm{s}$.

\begin{tabular}{|c|c|c|c|c|c|c|c|}
\hline WA & EXATO & ESTIM. & D.PADRÃO & PARAM. ELAS. & EXATOS & ESTIM. & D.PADRÃO \\
\hline$\varepsilon_{x}$ & $9,29 \mathrm{E}-002$ & $5,37 \mathrm{E}-002$ & $8,84 \mathrm{E}-002$ & $A_{11}$ & 18,46 & 17,25 & 2,81 \\
\hline$\varepsilon_{y}$ & $9,29 \mathrm{E}-002$ & $4,92 \mathrm{E}-002$ & 0,11 & $A_{22}$ & 18,46 & 17,10 & 3,53 \\
\hline$\varepsilon_{z}$ & $5,23 \mathrm{E}-003$ & $4,21 \mathrm{E}-003$ & $2,92 \mathrm{E}-003$ & $A_{33}$ & 15,73 & 15,69 & 0,19 \\
\hline$\delta_{x}$ & $8,82 \mathrm{E}-002$ & $3,18 \mathrm{E}-002$ & 0,14 & $A_{13}+2 A_{55}$ & 16,94 & 16,07 & 2,32 \\
\hline$\delta_{y}$ & $8,82 \mathrm{E}-002$ & $2,52 \mathrm{E}-002$ & 0,18 & $A_{23}+2 A_{44}$ & 16,94 & 15,96 & 2,85 \\
\hline$\delta_{z}$ & 0,18 & $9,88 \mathrm{E}-002$ & 0,17 & $A_{12}+2 A_{66}$ & 18,45 & 17,11 & 2,72 \\
\hline
\end{tabular}

Tabela 3: Valores exatos e estimados dos parâmetros WA, valores exatos e estimados dos parâmetros elásticos normalizados pela densidade $\left(\mathrm{em} \mathrm{m}^{2} / \mathrm{s}^{2}\right)$ e seus respectivos desvios padrões amostral. As velocidades das ondas $\mathrm{Pe}$ S são: $\alpha$ sem ruído $=3,946 \mathrm{~km} / \mathrm{s}$; Velocidade $\alpha$ com ruído $=3,945 \mathrm{~km} / \mathrm{s}$; Velocidade $\beta$ sem ruído $=2,27 \mathrm{~km} / \mathrm{s}$. 